NASA/TM-2001-211288

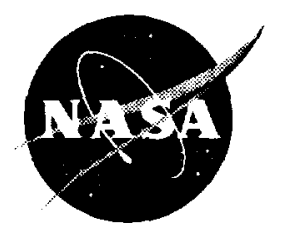

\title{
The Development of Surface Roughness and Implications for Cellular Attachment in Biomedical Applications
}

Bruce Banks, Sharon Miller, and Kim de Groh

Glenn Research Center, Cleveland, Ohio

Amy Chan

Ohio Aerospace Institute, Brook Park, Ohio

Mandeep Sahota

Cleveland State University, Cleveland, Ohio

Prepared for the

2001 Fall Meeting

sponsored by the Materials Research Society

Boston, Massachusetts, November 26-30, 2001

National Aeronautics and

Space Administration

Glenn Research Center 
Trade names or manufacturers' names are used in this report for identification only. This usage does not constitute an official endorsement, either expressed or implied, by the National Aeronautics and Space Administration.

Available from

NASA Center for Aerospace Information

7121 Standard Drive

Hanover, MD 21076
National Technical Information Service 5285 Port Royal Road Springfield, VA 22100 


\title{
The Development of Surface Roughness and Implications for Cellular Attachment in Biomedical Applications
}

\author{
Bruce Banks, Sharon Miller, and Kim de Groh \\ National Aeronautics and Space Administration \\ Glenn Research Center \\ Cleveland, Ohio 44135 \\ Amy Chan \\ Ohio Aerospace Institute \\ Brook Park, Ohio 44142 \\ Mandeep Sahota \\ Cleveland State University \\ Cleveland, Ohio 44115
}

\begin{abstract}
The application of a microscopic surface texture produced by ion beam sputter texturing to the surfaces of polymer implants has been shown to result in significant increases in cellular attachment compared to smooth surface implants in animal studies. A collaborative program between NASA Glenn Research Center and the Cleveland Clinic Foundation has been established to evaluate the potential for improving osteoblast attachment to surfaces that have been microscopically roughened by atomic oxygen texturing. The range of surface textures that are feasible depends upon both the texturing process and the duration of treatment. To determine whether surface texture saturates or continues to increase with treatment duration, an effort was conducted to examine the development of surface textures produced by various physical and chemical erosion processes. Both experimental tests and computational modeling were performed to explore the growth of surface texture with treatment time. Surface texturing by means of abrasive grit blasting of glass, stainless steel and polymethylmethacrylate surfaces was examined to measure the growth in roughness with grit blasting duration by surface profilometry measurements. Laboratory tests and computational modeling was also conducted to examine the development of texture on Aclar ${ }^{\circledR}$ (chlorotrifluoroethylene) and Kapton $®$ polyimide,

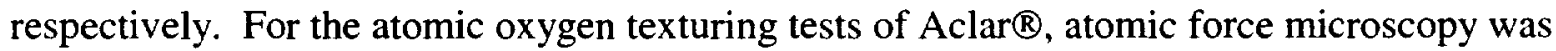
used to measure the development of texture with atomic oxygen fluence. The results of all the testing and computational modeling support the premise that development of surface roughness obeys Poisson statistics. The results indicate that surface roughness does not saturate but increases as the square root of the treatment time.
\end{abstract}

\section{INTRODUCTION}

The degree of cellular attachment to polymer surfaces has been shown to significantly increase by providing a textured surface as opposed to a smooth surface for peritoneal implants in rats [1-2]. Such tests were performed by comparing argon ion beam sputter textured and sputter polished polytetrafluoroethylene (PTFE Teflon ${ }^{\circledR}$ ) implant surfaces. The surface texturing produced submicron to multimicron sized cones on what would otherwise be rather 
smooth surfaces. The number of cells attached per $4 \times 10^{4} \mathrm{~cm}^{2}$ was only $\sim 12$ for ion sputter polished PTFE, but was 270 for ion beam sputter textured PTFE after 2 days of implantation [1-2]. The principal cells attached were macrophages, lymphocytes and to a lesser degree mast cells.

Atomic oxygen has been shown to produce surface textures in almost all hydrocarbon or halocarbon polymers. The resulting textures are quite similar to sputter textured surfaces, but much easier to produce. Figures 1 and 2 compare the surface texture of ion beam sputter

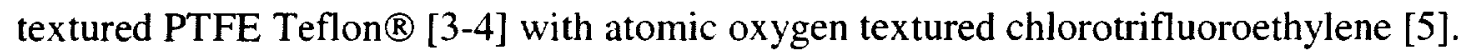

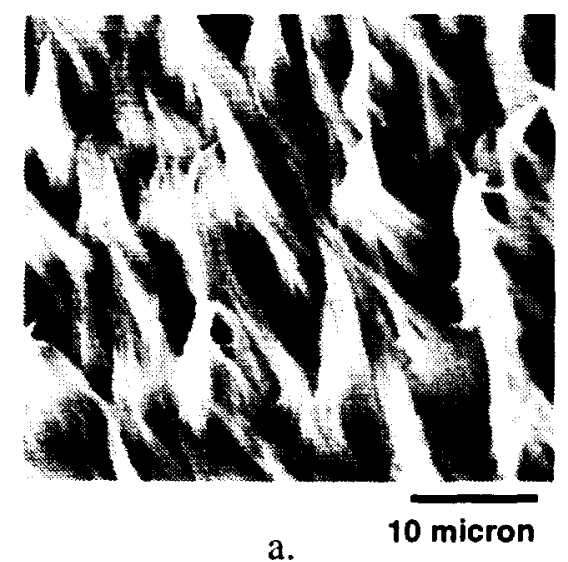

Figure 1. Comparison of the surface texture of fluoropolymers produced through ion beam sputtering and atomic oxygen texturing, a). argon ion beam sputter textured PTFE Teflon ${ }^{\circledR}$, and b). low Earth orbital atomic oxygen textured chlorotrifluoroethylene retrieved from the Long Duration Exposure Facility.

Both directed atomic oxygen beams and isotropic atomic oxygen produces textured surfaces in hydrocarbon as well as halocarbon polymers. However, the aspect ratio of the texture is greater for the directed atomic oxygen exposures. Because the degree of surface texture appears to play such an important role in cellular attachment, it is desirable to explore the range of surface roughness that may be possible for various materials and texturing processes. For some roughening processes such as abrasive sanding using sandpaper, one would expect that the surface roughness would increase to a limiting value because the height of the peaks and the depth of the valleys are somewhat dependent on each other and the grit size of the sandpaper. However, random microscopic erosive processes where height of the peaks and the depth of the valleys are independent of each other should allow surface texture to gradually increase with surface treatment. One might expect that such surface texturing processes include abrasive grit blasting, atomic oxygen texturing and ion beam sputter texturing. If the development of surface roughness occurs by spatially independent erosion processes, then the growth of the roughness should obey Poisson statistics. In such surface treatment processes it is postulated that surface roughness increases as the square root of the treatment time. Monte Carlo computational modeling of atomic oxygen exposed Kapton $®$ polyimide has shown that surface roughness should increase at a less than proportional rate with atomic oxygen fluence for directed atomic oxygen exposure [6]. 
The objective of this investigation was to explore the growth of surface roughness with treatment duration for various surface-roughening techniques and for various substrates. The premise is that spatially independent erosion processes obey Poisson statistics and thus RootMean-Squared (RMS) roughness should increase proportionally to the square root of the treatment duration. The resulting knowledge may allow one to know if there is a limit to the surface roughness that is possible for various roughening techniques and on various types of materials such as polymers, metals and glass. The information will also be useful for an existing collaborative research program between NASA Glenn Research Center and the Cleveland Clinic Foundation concerning the adhesion and spreading of osteosarcoma cells on textured Aclar $B$ chlorotrifluoroethylene.

\section{APPARATUS AND PROCEDURE}

Surface texturing was performed by two different processes: abrasive grit blasting and isotropic atomic oxygen attack in an RF plasma asher. Materials that were textured by abrasive grit blasting included glass microscope slides, 300 series stainless steel and polymethylmethacrylate. Isotropic atomic oxygen was used to surface texture Aclar ${ }^{\circledR}$ clorotrifluoroethylene.

\section{Abrasive grit blasting}

Aluminum oxide abrasive grit was used in a conventional abrasive grit-blasting system to explore RMS roughness growth with grit blasting time. The diameters of these particles ranged from 157 to $3150 \mu \mathrm{m}$ with an average maximum diameter of $795 \mu \mathrm{m}$. The three materials that were textured were placed in an abrasive grit blasting system in which the nozzle was placed in a rigid structure such that it was located $38.1 \mathrm{~cm}$ from the sample surfaces with the abrasive grit flowing in a horizontal direction. The test sample surfaces were perpendicular to the grit flow direction and exposed to various durations of abrasive grit blasting with the samples being taped to a holder using vinyl electrical tape to prevent the samples from being blown away or moving as a result of the air flow. The grit blasting gun air pressure was set at $2.07 \times 10^{5} \mathrm{~Pa} \mathrm{(30} \mathrm{psi)}$ for the glass slides, at $3.45 \times 10^{5} \mathrm{~Pa}(50 \mathrm{psi})$ for the stainless steel samples, and at $2.76 \times 10^{5} \mathrm{~Pa}$ (40 psi) for the polymethylmethacrylate samples. The microscope slides were $1 \mathrm{~mm}$ thick $\mathrm{x}$ $2.54 \mathrm{~cm}$ wide $x 7.5 \mathrm{~cm}$ long. The 300 series stainless steel samples were $3 \mathrm{~mm}$ thick $\times 3.2 \mathrm{~cm}$ wide $\mathrm{x} 7.5 \mathrm{~cm}$ long. Lastly, the size of the polymethylmethacrylate samples was $4.8 \mathrm{~mm}$ thick $\mathrm{x}$ $3.2 \mathrm{~cm}$ wide $\mathrm{x} 8.3 \mathrm{~cm}$ long.

\section{Isotropic atomic oxygen exposure in an RF plasma asher}

A 100-watt SPI Plasma Prep II RF (13.56 MHz) plasma asher operated on air at $16.6 \mathrm{~Pa}$ (125 millitorr), the typical operating pressure, was used to atomic oxygen texture $2.54 \mathrm{~cm}$ ( 1 inch) diameter $x 0.127 \mathrm{~cm}\left(0.005\right.$ inch) thick Acylar ${ }^{\circledR}$ clorotrifluoroethylene samples. Atomic oxygen fluence measurements were made using $0.127 \mathrm{~mm}$ thick polyimide Kapton® $\mathrm{H}$ fluence witness samples. The samples were vacuum dehydrated to accurately determine mass loss as a function of time for various texturing durations. The asher was operated at a fixed condition such that the Kapton ${ }^{\circledR}$ effective flux for all the exposures was $7.21 \times 10^{15}$ atoms $/\left(\mathrm{cm}^{2} \mathrm{~s}\right)$. The atomic oxygen fluence for each exposure was measured using ASTM E 2089-00 Standard Practices. 


\section{Surface roughness characterization}

The RMS surface roughness of samples exposed to grit blasting was measured using a Dektak IIA profilometer using a scan length of $1 \mathrm{~mm}$. Samples exposed to isotropic atomic oxygen in the RF plasma asher were characterized for surface roughness using a Park Scientific Auto Probe LS atomic force microscope (AFM) operated in the contact mode. The AFM was used for characterizing the surface roughness of clorotrifluoroethylene to prevent surface damage from occurring in this low elastic modulus material. Tests were also conducted to identify a scan length for the profilometer, as well as the AFM, that produced RMS values that were characteristic of the true surface roughness as opposed to the pristine surface waviness.

\section{RESULTS AND DISCUSSION}

The RMS roughness for the grit blast textured surfaces was found to be dependent upon the scan length used during profilometry for scan lengths greater than $100 \mu \mathrm{m}$. This was thought to be caused by the gradual waviness of the surface as opposed to true microscopic roughness. Thus a scan length of $100 \mu \mathrm{m}$ was used for RMS roughness characterization of these surfaces. Figures 2, 3, and 4 show the resulting RMS roughness obtained for grit blasting of glass microscope slides, 300 series stainless steel and polymethylmethacrylate, respectively.

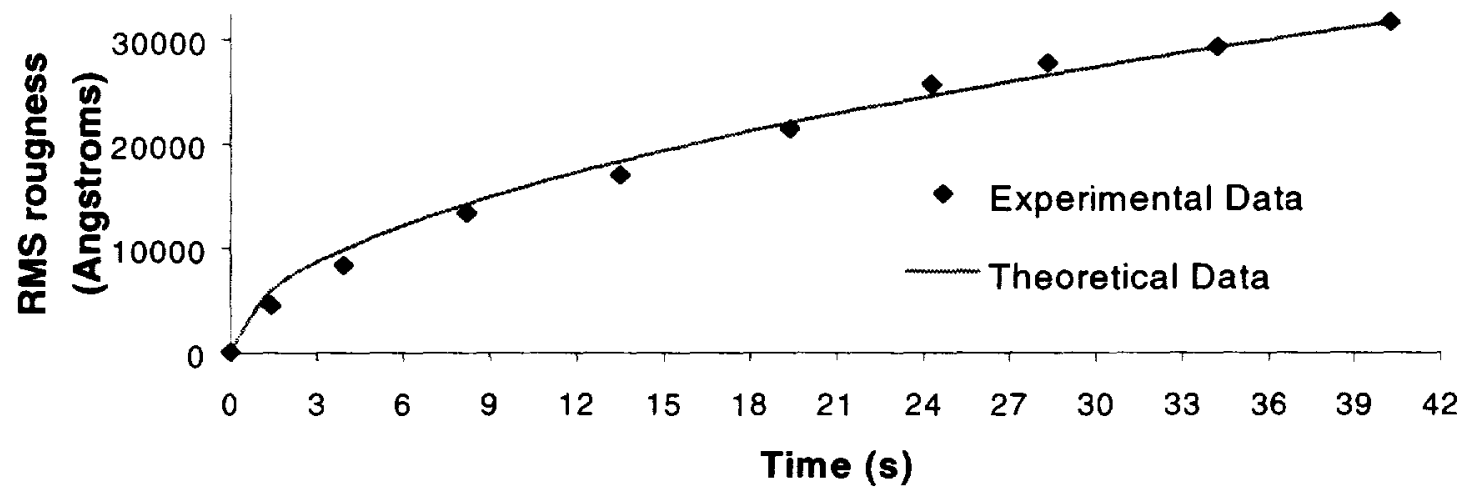

Figure 2. RMS roughness of grit blasted glass microscope slide surfaces as a function of grit blasting duration and Poisson theory fit to data. 


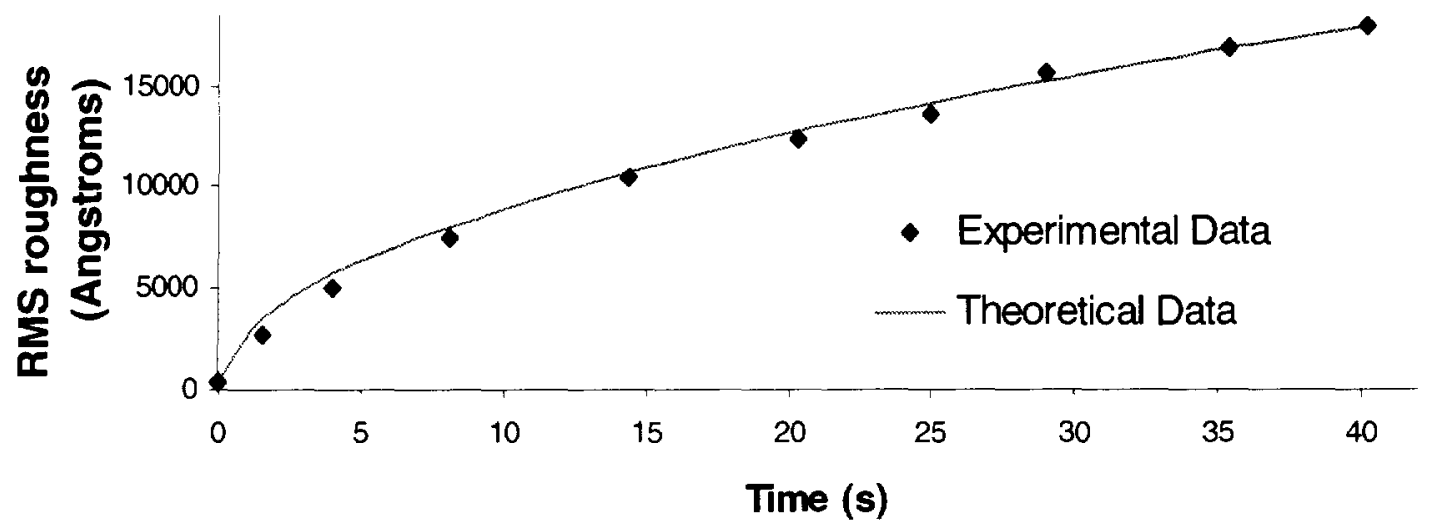

Figure 3. RMS roughness of grit blasted stainless steel as a function grit blasting duration and Poisson theory fit to data.

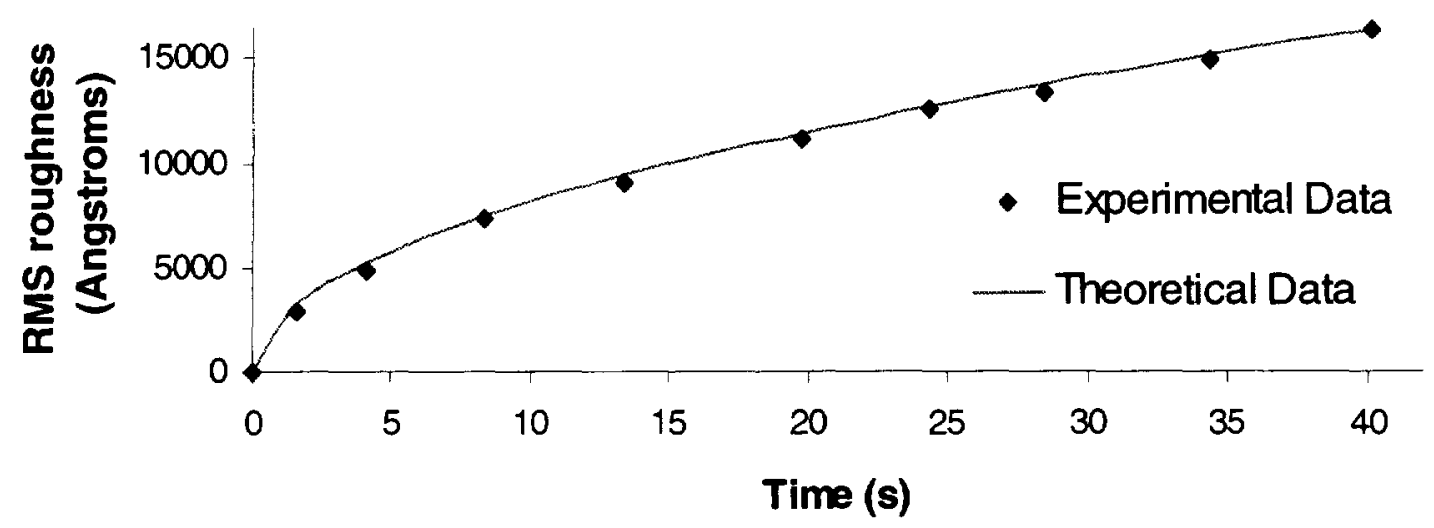

Figure 4. RMS roughness of grit blasted polymethylmethacrylate as a function grit blasting duration and Poisson theory fit to data. 
Figure 5 shows the resulting RMS roughness obtained for isotropic atomic oxygen exposure of Aclarß chlorotrifluoroethylene.

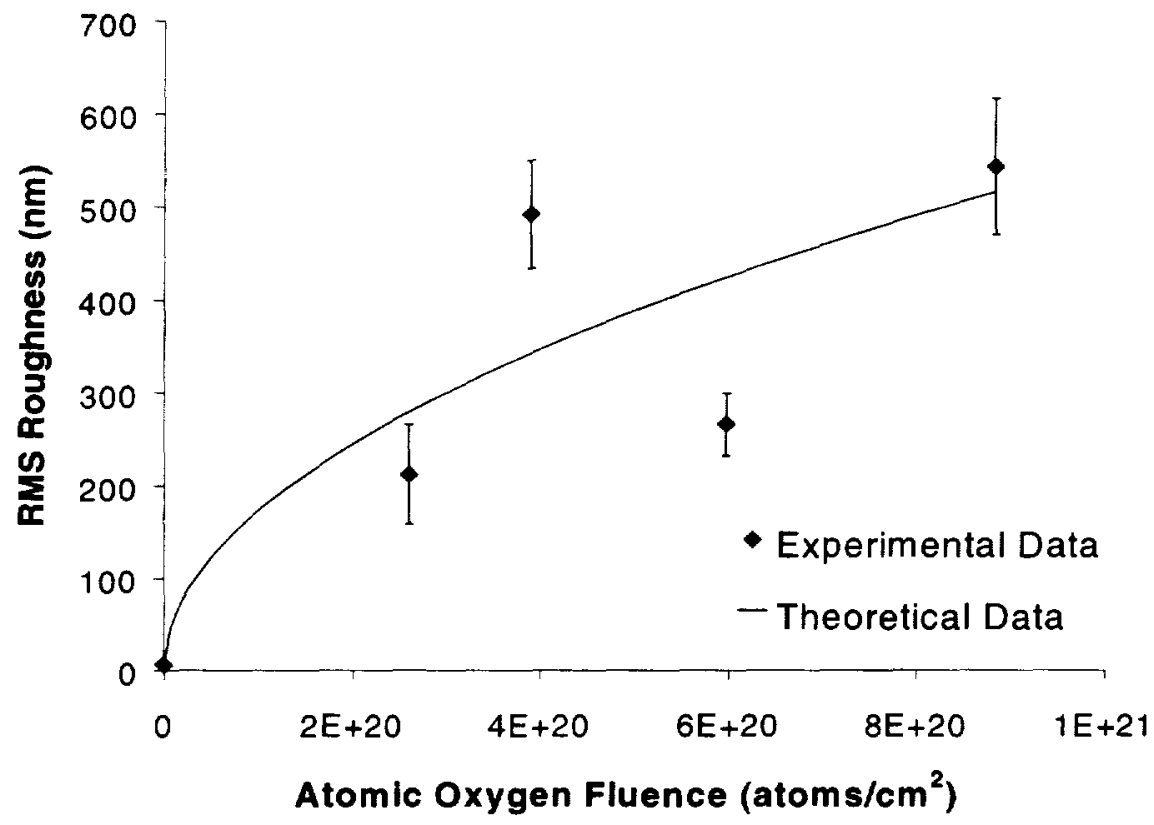

Figure 5. RMS roughness of Aclar ${ }^{\circledR}$ chlorotrifluoroethylene as a function of isotropic atomic oxygen fluence and Poisson theory fit to data.

As can be seen from all four materials, there appears to be reasonable agreement with a square-root-of-treatment Poisson theory fit to the experimental data for development of surface roughness with treatment duration. Although the rate of development of surface roughness is dependent upon the texturing particles (abrasive grit or oxygen atoms), impact conditions (pressure or energy) and substrate material, the RMS roughness simply can be predicted by a different constant of proportionality that is multiplied by the square root of the treatment duration to obtain a reasonable fit to the experimental data. Thus, for such spatially independent erosion processes, the surface roughness does not reach a limit with treatment duration but rather any degree of surface roughness should be achievable with sufficient duration of treatment.

Preliminary results of isotropic atomic oxygen treated Aclar ${ }^{\circledR}$ to a Kapton $\circledast \mathrm{H}$ effective fluence of up to $7.4 \times 10^{-20}$ atoms $/ \mathrm{cm}^{2}$ have shown significant increases in adhesion of osteosarcoma cells over untreated smooth surface Aclarß samples [7-8]. 


\section{SUMMARY}

The dependence of surface roughness upon treatment duration was explored using abrasive grit blasting of glass microscope slides, 300 series stainless steel and polymethyl methacrylate and isotropic atomic oxygen exposure of Aclar ${ }^{\circledR}$ chlorotrifluoroethylene. There appears to be reasonable surface roughness agreement with a square-root-of-treatment Poisson theory fit to the experimental data thus indicating that using such surface roughening processes, where spatial independence occurs, allows one to obtain any degree of surface roughness by simply adjusting the treatment duration. Preliminary results of atomic oxygen treated Aclar ${ }^{\circledR}$ samples indicate significant increases in osteosarcoma cell adhesion in comparison to untreated smooth surfaces.

\section{REFERENCES}

1. Banks, B. A., Chapter 11 in Ion Bombardment Modification of Surfaces in Biomedical Applications, edited by O. Auciello and R. Kelly, Elsevier Publishing Co., 1984.

2. Picha, G. J., "Tissue Response to Peritoneal Implants", NASA CR-159817, June 1980.

3. Banks, B. A., Chapter 17. entitled "Topography: Texturing Effects" in Handbook of Ion Beam Processing Technology, edited by Jerome J. Cuomo, Stephen M. Rossnagel, and Harold R. Kaufman; Noyes Publications, 1988.

4. Banks, B. A., "Ion Beam Applications Research - A 1981 Summary of Lewis Research Center Programs," NASA TM No. 81721; presented at the 15th IEP Conference cosponsored by the AIAA, Japan Society for Aeronautical and Space Sciences, and Deutsche Gesselschaft for Luft und Raumfahrt, Las Vegas, Nevada, April 21-23, 1981.

5. de Groh, K. K., Banks, B. A., and Smith, D. C., "Environmental Durability Issues for Solar Power Systems in Low Earth Orbit", Proceedings of the 1995 International Solar Energy Conference, Lahaina, Maui, Hawaii, NASA TM 106775, March 19-24, 1995.

6. Banks, B. A., Stueber, T.J., Snyder, S. A., Rutledge, S. K., and Norris, M. J., "Atomic Oxygen Erosion Phenomena," presented at the American Institute of Aeronautics \& Astronautics, Defense and Space Programs Conference, Huntsville, AL, Sept. 23-25, 1997.

7. ASTM E 2089-00 Standard Practices for Ground Laboratory Atomic Oxygen Interaction Evaluation of Materials for Space Applications, approved May 10, 2000, published June 2000.

8. Personal communication with Ron Midura of the Cleveland Clinic Foundation 


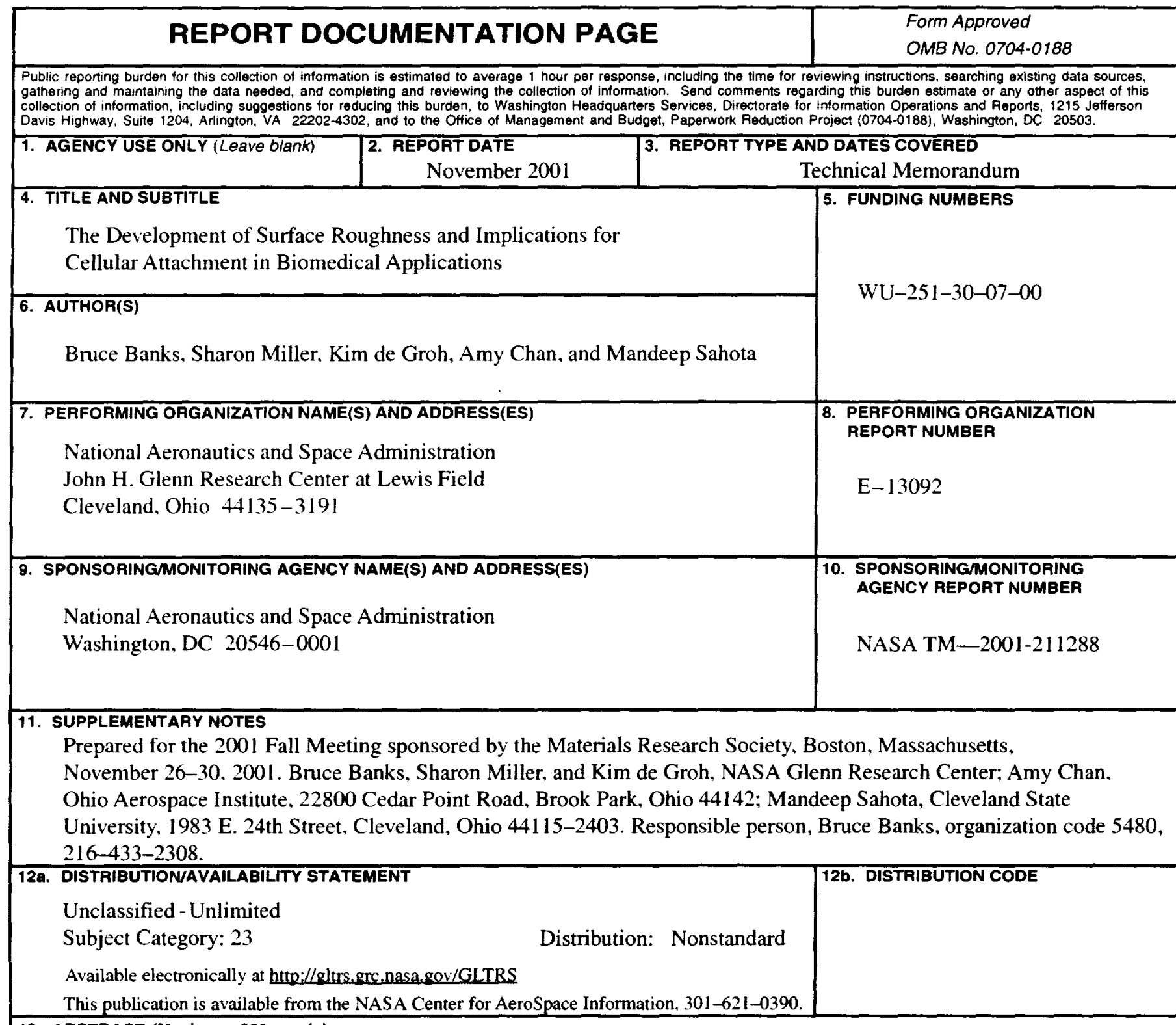

13. ABSTRACT (Maximum 200 words)

The application of a microscopic surface texture produced by ion beam sputter texturing to the surfaces of polymer implants has been shown to result in significant increases in cellular attachment compared to smooth surface implants in animal studies. A collaborative program between NASA Glenn Research Center and the Cleveland Clinic Foundation has been established to evaluate the potential for improving osteoblast attachment to surfaces that have been microscopically roughened by atomic oxygen texturing. The range of surface textures that are feasible depends upon both the texturing process and the duration of treatment. To determine whether surface texture saturates or continues to increase with treatment duration, an effort was conducted to examine the development of surface textures produced by various physical and chemical erosion processes. Both experimental tests and computational modeling were performed to explore the growth of surface texture with treatment time. Surface texturing by means of abrasive grit blasting of glass, stainless steel, and polymethylmethacrylate surfaces was examined to measure the growth in roughness with grit blasting duration by surface profilometry measurements. Laboratory tests and computational modeling was also conducted to examine the development of texture on Aclar ${ }^{\circledR}$ (chlorotrifluoroethylene) and Kapton ${ }^{\circledR}$ polyimide, respectively. For the atomic oxygen texturing tests of Aclarß . atomic force microscopy was used to measure the development of texture with atomic oxygen fluence. The results of all the testing and computational modeling support the premise that development of surface roughness obeys Poisson statistics. The results indicate that surface roughness does not saturate but increases as the square root of the treatment time.

\section{SUBJECT TERMS}

Surface roughness; Oxygen atoms; Profilometers; Grit

\begin{tabular}{l} 
15. NUMBER OF PAGES \\
\hline 13 \\
\hline 16. PRICE COOE \\
\hline 20. LIMITATION OF ABSTRACT \\
\hline
\end{tabular}

\begin{tabular}{|c|c|}
\hline 17. SECURITY CLASSIFICATION \\
OF REPORT \\
Unclassified
\end{tabular}$\quad \begin{gathered}\text { 18. SECURITY CLASSIFICATION } \\
\text { OF THIS PAGE } \\
\text { Unclassified }\end{gathered}$

